\title{
Education and practice gaps on atrial fibrillation and anticoagulation: a survey of cardiovascular nurses
}

\author{
Caleb Ferguson ${ }^{1 *}$, Sally C. Inglis², Phillip J. Newton², Sandy Middleton ${ }^{3,4}$, Peter S. Macdonald ${ }^{5}$
} and Patricia M. Davidson ${ }^{2,6}$

\begin{abstract}
Background: Patients' knowledge of their atrial fibrillation (AF) and anticoagulation therapy are determinants of the efficacy of thromboprophylaxis. Nurses may be well placed to provide counselling and education to patients on all aspects of anticoagulation, including self-management. It is important that nurses are well informed to provide optimal education to patients. Current practice and knowledge of cardiovascular nurses on AF and anticoagulation in the Australian and New Zealand (ANZ) context is not well reported.

This study aimed to; 1) Explore the nurse's role in clinical decision making in anticoagulation in the setting of AF; 2) Describe perceived barriers and enablers to anticoagulation in AF; 3) Investigate practice patterns in the management of anticoagulation in the ANZ setting; 4) Assess cardiovascular nurses' knowledge of anticoagulation.
\end{abstract}

Methods: A paper-based survey on current practices and knowledge of AF and anticoagulation was distributed during the Australian Cardiovascular Nursing College (ACNC) Annual Scientific Meeting, February 2014. This survey was also emailed to Cardiovascular Trials Nurses throughout New South Wales, Australia and nursing members of the Cardiac Society of Australia and New Zealand (CSANZ).

Results: There were 41/73 (56 \%) respondents to the paper-based survey. A further 14 surveys were completed online via nurse members of the CSANZ, and via an investigator developed NSW cardiovascular trials nurse email distribution list. A total of 55 surveys were completed and included in analyses. Prior education levels on AF, stroke risk, anticoagulation and health behaviour modification were mixed. The $\mathrm{CHA}_{2} \mathrm{DS}_{2} \mathrm{VASC}$ and HAS-BLED risk stratification tools were reported to be underused by this group of clinicians. Reported key barriers to anticoagulation included; fears of patients falling, fears of poor adherence to medication taking and routine monitoring. Patient self-monitoring and self-management were reported as underutilised. ANZ cardiovascular nurses reported their key role to be counselling and advising patients on therapy regimens. Anticoagulant-drug interaction knowledge was generally poor.

Conclusion: This study identified poor knowledge and practice in the areas of AF and anticoagulation. There is scope for improvement for cardiovascular nurses in ANZ in relation to AF and anticoagulation knowledge and practice.

Keywords: Clinical practice, Anticoagulant knowledge, Anticoagulation, Atrial fibrillation, Education, Survey methods, Patient education, Self-management

* Correspondence: caleb.ferguson@uts.edu.au

${ }^{1}$ Faculty of Health, University of Technology Sydney, Sydney, Australia

Full list of author information is available at the end of the article 


\section{Background}

Atrial fibrillation (AF) is the most common cardiac rhythm irregularity and increases stroke risk three to five-fold [1]. The population prevalence is estimated at $2.3-3.4 \%$. The lifetime risk of AF is approximately 1 in 4 [1]. This incidence increases with age and rises to affect $11 \%$ of the population over 80 years [2]. This primarily cardiogeriatric condition is characterised by chaotic electrical activity in the upper chambers of the heart. Stroke and thromboembolism are major complications of AF. Evidence-based interventions to reduce stroke risk in AF include anticoagulation and the insertion of a left atrial appendage (LAA) device, as well as the rhythm control methods such as cardioversion and catheter ablation [3]. Oral anticoagulation is the most common way to reduce stroke risk in individuals with AF. Whilst the recent advent of new oral anticoagulants (NOACs) such as the thrombin inhibitor dabigatran, and factor $\mathrm{Xa}$ inhibitors rivaroxaban and apixaban have held the promise of simplified dosing without the need for frequent blood testing, concerns persist of bleeding risk and the lack of any reversal agent for these agents [3]. To date, warfarin remains the most commonly used oral anticoagulant, and its use is inherently burdensome. This burden is often related to the need for routine monitoring, adaptation of lifestyle habits and more often than not; complex dosing requirements [4]. The quality of overall anticoagulation quality can be assessed by an individual's time in therapeutic range. An individual with AF should aim to maintain their INR between 2 and 3 [5, 6]. However, many individuals may find this challenging to achieve due to a variety of factors. Unstable INRs are likely to be a consequence of medication, food or lifestyle interactions [7]. Quality anticoagulation is reliant on patients and caregivers' knowledge of their chronic condition and anticoagulation therapy [8]. The often lifetime duration of treatment increases the complex issues of adherence, and emphasises the need for education refreshment throughout all care settings. Previous studies have highlighted that clinicians including physicians, pharmacists, dieticians and nurses fail to meet adequate knowledge levels to provide accurate and up-to-date information to patients $[9,10]$. A recent European study drew attention to the need for improvement in cardiovascular nurses' knowledge and practice on oral anticoagulant therapy [9]. With an increasing prevalence of AF, there is greater need for innovative strategies to improve patient outcomes. Strategies may include patient self-testing and self-management. The success of these strategies are dependent upon appropriate patient selection [11]. Patients must have good manual dexterity and cognitive abilities [12]. Further, they must be adept in managing the device; interpreting, understanding and taking action based on results. Self-testing and selfmanagement should not be discounted by clinicians, as a method to improve knowledge, self-efficacy, overall quality of anticoagulation, and patient outcomes [11]. Nurses account for greater than $50 \%$ of the health workforce in Australia and often spend the most time with patients providing clinical care. They are experienced in counselling, therefore, may be well-placed to provide patient education on anticoagulation and promote selfmanagement during regular healthcare interactions.

\section{Study aim}

The aim of this study was to:

1) Explore the nurse's role in clinical decision-making in anticoagulation in the setting of AF.

2) Describe perceived barriers and enablers to anticoagulation in AF.

3) Investigate practice patterns in the management of anticoagulation.

4) Assess cardiovascular nurses' knowledge of anticoagulation.

\section{Methods}

\section{Design, setting and sample}

Data were collected by survey methods. The survey was conducted at the 8th Annual Scientific Meeting of the Australian Cardiovascular Nursing College, Gold Coast, Australia on 22nd Feb 2014. All delegates attending on this date were invited to participate in the study. Additional responses were sought via an email distribution list of the Nurses Council of the Cardiac Society of Australia and New Zealand, and a state-wide cardiovascular research nurse email distribution list. Additionally, nurses working in a single site CCU of a metropolitan teaching hospital were invited to participate. (Refer to Table 1 for sampling frame response).

\section{Measurements and item generation}

A self-report questionnaire, recently used during a European study of cardiovascular nurses was used to assess variables related to warfarin-drug, warfarin-food interactions and knowledge on novel anticoagulants and

Table 1 Final sampling frame response

\begin{tabular}{llll}
\hline Distribution method & $\begin{array}{l}\text { Distribution } \\
\text { sample }\end{array}$ & $\begin{array}{l}\text { Number of } \\
\text { responses }\end{array}$ & $\begin{array}{l}\text { Response } \\
\text { rate }\end{array}$ \\
\hline ACNC Conference & 73 & 41 & $56 \%$ \\
CSANZ CNC Email list serve & 320 & 2 & $0.625 \%$ \\
$\begin{array}{l}\text { HF Coordinator Email } \\
\text { distribution list }\end{array}$ & 31 & 9 & $29 \%$ \\
$\begin{array}{l}\text { Cardiology Ward } \\
\text { Total }\end{array}$ & 34 & 3 & $9 \%$ \\
\hline
\end{tabular}

Legend: ACNC Australian Cardiovascular Nursing College, CSANZ CNC Cardiac Society of Australia and New Zealand Cardiovascular Nursing Council, HF Heart Failure 
self-management [9]. Permission to reproduce these survey items was approved by the corresponding author. The original questionnaire was reported as demonstrating good face validity. Study investigators reviewed the original survey used in Europe, and felt that the variables and items included were applicable to the ANZ setting, given the similarities in westernised healthcare systems and availability of pharmacological agents at the time of the survey. Additional investigator developed questions were included; these were developed following consultation with expert cardiovascular nurses and an extensive review of the literature. Some questions were adapted from other surveys that addressed barriers to anticoagulation or elicited the cardiovascular nurse's role in decision-making around anticoagulation therapy [13]. The questionnaire was distributed in English.

\section{Data collection}

All delegates were provided with a paper-based survey on their chair during the session and invited by the convenor to participate. Attendees were asked to place the completed questionnaires in a designated collection box following the session. Subsequent to the conference, the same survey was electronically distributed to nursing members of the Cardiac Society of Australia and New Zealand and via a state-wide cardiovascular research nurse email distribution list. Additionally, nurses working in the hospital CCU were invited to participate. The hospital site was selected for inclusion, due to the locality of the site in relation to the research team's clinical practice setting. Online survey methods have previously been used to gain understanding of practice patterns in the ANZ setting [14]. Therefore, the research team believed this would yield worthy response and enhance findings from the paper-based survey. To address the potential for selection bias, a poster and box was placed in the ward setting for clinicians to provide responses. A notification for completion of the electronic survey was sent electronically once, and no reminders were sent. Within the electronic survey information, participants were advised that this survey was previously undertaken at the recent $\mathrm{ACNC}$ conference, and asked not to complete if they had already participated.

\section{Data management and data analysis}

The online survey was conducted using the web-based SurveyMonkey ${ }^{\text {TIT }}$ platform (www.surveymonkey.com) and remained open until 12/05/2014. Paper based surveys were manually entered into the electronic system; this assisted in accounting for missing values. The survey ascertained the basic demographic and education characteristics of nurses related to highest qualification and length of time working in cardiovascular nursing. Descriptive analyses were used to describe the sample and the responses to study variables.

\section{Ethical considerations}

This study was approved by the St Vincent's Hospital, Sydney (Ref: LNR/12/SVH/62) and University of Technology Sydney (Ref: 2013000181) human research ethics committees. Approval was provided for both online and paper-based surveys at the conference. The executive committee of the Australian Cardiovascular Nursing College approved survey distribution during the conference event. All conference attendees were informed of the aims of the study. Informed consent was implied by the completion of the survey. No identifying information was collected from the participants to assure confidentiality.

\section{Results}

\section{Sample characteristics, demographic information and experience}

A total of 55 responses were included in the analyses. The table above identifies most responses were from the ACNC conference, with a response rate of $56 \%$. Unfortunately, e-survey distributed by CSANZCNC once received two responses, notwithstanding the reach of the email to 320 members. A possible reason for this may be that some of the members of CSANZCNC are also members of $\mathrm{ACNC}$, and had attended the conference, and previously participated in the survey. Most respondents were female $86 \%(n=47)$, the majority of respondents $91 \%(n=50)$ came from the three most populated states in Australia (New South Wales, Victoria and Queensland). The remaining respondents were from New Zealand $9 \%$ $(n=5)$. The majority worked in a metro area $71 \%(n=39)$, and held a Bachelor degree qualification or above $85 \%$ $(n=47) .33 \%(n=18)$ identified their current role as Registered Nurse (RN). Though, the seniority of the clinicians was also reflected by the number in expert positions, $36 \%(n=36)$ identified as Clinical Nurse Consultants or Nurse Practitioners. Three respondents were not clinicians and were employed in the higher education \& research sectors. Most $77 \%(n=40)$ had over 10 years of clinical experience, and $62 \%(n=34)$ had worked in cardiovascular nursing specialty practice for more than 10 years. Baseline demographic information is summarised in Table 2.

Participation in formal educational programs was reported to be $41-61 \%$ across four associated topics. $48 \%$ had attended a previous education program about AF, $41 \%$ about stroke risk, $57 \%$ about anticoagulation and $61 \%$ about health behaviour modification. Previous education participation is summarised in Table 3 .

\section{Adverse outcomes}

Fifty percent of respondents had cared for a patient with AF who had experienced an intracranial haemorrhage when receiving anticoagulation. And $74 \%$ of respondents had cared for a patient with AF who had experienced a 
Table 2 Characteristics of cardiovascular nurses $(n=55)$

\begin{tabular}{|c|c|}
\hline Demographic variable & $n(\%)$ \\
\hline Female $(n=55)$ & $47(86)$ \\
\hline \multicolumn{2}{|l|}{ Highest level of education ( $n=55$ ) } \\
\hline $\begin{array}{l}\text { - Nursing training } \\
\text { - Bachelor degree } \\
\text { - Graduate certificate } \\
\text { - Master's degree } \\
\text { - PhD } \\
\text { - Other }\end{array}$ & $\begin{array}{l}5(9) \\
15(27) \\
11(20) \\
16(29) \\
5(9) \\
3(6)\end{array}$ \\
\hline \multicolumn{2}{|l|}{ Work location ( $n=55$ ) } \\
\hline $\begin{array}{l}\text { - Metro } \\
\text { - Regional or rural }\end{array}$ & $\begin{array}{l}39(70) \\
16(29)\end{array}$ \\
\hline \multicolumn{2}{|l|}{ Country of workplace $(n=55)$} \\
\hline $\begin{array}{l}\text { - New South Wales } \\
\text { - Australian Capital Territory } \\
\text { - Victoria } \\
\text { - Western Australia } \\
\text { - Northern Territory } \\
\text { - Queensland } \\
\text { - Tasmania } \\
\text { - South Australia } \\
\text { - New Zealand }\end{array}$ & $\begin{array}{l}24(44) \\
0 \\
4(7) \\
0 \\
0 \\
22(40) \\
0 \\
0 \\
5(9)\end{array}$ \\
\hline \multicolumn{2}{|l|}{ Area of specialty practice $(n=55)$} \\
\hline $\begin{array}{l}\text { - Chronic Heart Failure } \\
\text { - Acute Coronary Syndrome } \\
\text { - Coronary Care Unit } \\
\text { - Cardiac Rehabilitation } \\
\text { - Cardiac Step Down } \\
\text { - Cath Lab } \\
\text { - Research } \\
\text { - Education } \\
\text { - General Medicine } \\
\text { - Other }\end{array}$ & $\begin{array}{l}21(38) \\
8(15) \\
20(36) \\
8(15) \\
5(9) \\
5(9) \\
3(6) \\
3(6) \\
3(6) \\
1(2)\end{array}$ \\
\hline \multicolumn{2}{|l|}{ Current position $(n=55)$} \\
\hline $\begin{array}{l}\text { - Registered Nurse } \\
\text { - Clinical Nurse Specialist } \\
\text { - Clinical Nurse Educator } \\
\text { - Clinical Nurse Consultant } \\
\text { - Nurse Practitioner } \\
\text { - Other }\end{array}$ & $\begin{array}{l}18(33) \\
12(22) \\
3(6) \\
10(18) \\
9(18) \\
3(6)\end{array}$ \\
\hline \multicolumn{2}{|c|}{ Years working in clinical practice $(n=52)$} \\
\hline 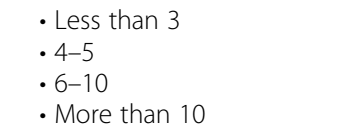 & $\begin{array}{l}2(4) \\
7(8) \\
6(12) \\
40(77)\end{array}$ \\
\hline \multicolumn{2}{|c|}{ Years working in cardiovascular nursing $(n=55)$} \\
\hline $\begin{array}{l}\cdot \text { Less than } 3 \\
\cdot 4-5 \\
\cdot 6-10 \\
\cdot \text { - More than } 10\end{array}$ & $\begin{array}{l}6(11) \\
2(4) \\
13(24) \\
34(62)\end{array}$ \\
\hline \multicolumn{2}{|c|}{ Years working in current department $(n=55)$} \\
\hline $\begin{array}{l}\cdot \text { Less than } 3 \\
\cdot 4-5 \\
\cdot 6-10 \\
\cdot \text { - More than } 10\end{array}$ & $\begin{array}{l}13(24) \\
13(24) \\
14(26) \\
15(27)\end{array}$ \\
\hline
\end{tabular}

Table 2 Characteristics of cardiovascular nurses $(n=55)$ (Continued)

Proportion of patients seen aged $65+(n=54)$

$\begin{array}{ll}\text { - Less than } 25 \% & 0(0) \\ \text { - } 26-50 \% & 4(7) \\ \text {. } 51-75 \% & 31(57) \\ \text { - } 76 \% \text { or more } & 19(35)\end{array}$

stroke whilst not receiving anticoagulation. Results are summarised in Table 4.

\section{Nurses role in decision making and anticoagulation}

Results of the nurses' role in decision making are summarised in Table 5. More than half of respondents (54\%, $n=29)$ said they were not involved in multidisciplinary team (MDT) discussions when making treatment decisions on anticoagulation management with patients with AF. Nearly half of respondents agreed (44\%, $n=24)$ or strongly agreed $(7 \%, n=4)$ that the risk of stroke versus the risk of bleeding was clearly articulated to patients at commencement of anticoagulation for stroke prevention in AF. Most disagreed (41 \%, n=22) or strongly disagreed (13\%,n=7) that they were unsure to advocate for thromboprophylaxis or not, when involved in team decisions. Most disagreed (50\%,n 27 ) or strongly disagreed ( $6 \%, n=3$ ) that it was difficult to decide where the benefits of thromboprophylaxis outweighed the risks of haemorrhage. Over half disagreed $(57 \%, n=30)$ that they did not feel they knew enough about the risks and benefits of different anticoagulants.

Most respondents $(57 \%, n=31)$ agreed that they took time to understand their patients views on the risks and benefits of anticoagulation, and that they (52\%, $n=28)$ felt that generally, their patients were well informed about their risks and benefits of anticoagulation at the time of commencement. Just under half ( $n=26,48 \%)$ agreed that their patients received comprehensive education about anticoagulation prior to discharge after hospitalisation. Stroke and bleeding risk stratification tools were reported to be underutilised by this group of clinicians. Specifically, only $25 \%(n=13)$ agreed that they used a $\mathrm{CHADS}_{2}$ or $\mathrm{CHA}_{2} \mathrm{DS}_{2}$-VASc tools, whilst only $18 \%(n=9)$ agreed they used the HAS-BLED tool, despite the fact that both are recommended in international

Table 3 Previous participation in educational programs

\begin{tabular}{ll}
\hline Education program & Yes (\%) \\
\hline Atrial fibrillation & $26(48)$ \\
Stroke risk & $20(41)$ \\
Anticoagulation & $29(57)$ \\
Health behaviour modification & $31(61)$ \\
\hline
\end{tabular}


Table 4 Clinical Factors

\begin{tabular}{ll}
\hline Variable (Clinical Factor) & $\mathrm{n}(\%)$ \\
\hline Estimated prevalence of AF in CHF & \\
$\cdot$ - Less than $25 \%$ & $3(6)$ \\
$\cdot 25-50 \%$ & $29(54)$ \\
$\cdot 51-75 \%$ & $19(35)$ \\
$\cdot$. $76 \%$ or more & $3(6)$ \\
Have cared for a patient with AF who has experienced & $27(50 \%)$ \\
an ICH whilst receiving anticoagulation & \\
Have cared for a patient with AF who has experienced & $39(74 \%)$ \\
a stroke whilst not receiving anticoagulation & \\
Actively involved in MDT discussions when making & $25(46 \%)$ \\
treatment decisions on anticoagulation management & \\
with patients with AF &
\end{tabular}

guidelines for anticoagulation in AF [5]. Over half ( $n=28$, $52 \%)$ agreed, or strongly agreed that they made use of a shared decision-making model of care to explain the risks and benefits of anticoagulation for stroke prevention in AF.

\section{Barriers to anticoagulation}

Barriers to anticoagulation are summarised in Table 6. Barriers to anticoagulation included fears of the patient falling ( $75 \%, n=39)$, fears of poor adherence to: routine monitoring (75 \%, $n=39)$ and medication taking (71\%, $n=36$ ). Other barriers included lack of social support (e.g. patient living alone, or a lack of a caregiver), (41\%, $n=21)$, and fears of poor literacy $(26 \%, n=13)$. Factors facilitating optimal management of thromboprophylaxis were identified, these are summarised in Tables 7 and 8.

\section{Practice patterns}

Results of practice patterns are summarised in Tables 9 and 10. Warfarin remains the most widespread anticoagulant used in daily practice for this cohort of clinicians $(100 \%, n=51)$. Less extensive use of the novel agents was reported. Only $16 \%(n=8)$ of respondents stated that most patients would be given a choice of anticoagulant, $82 \%(n=41)$, stated that 'some' patients may be offered new anticoagulants. $59 \%(n=29)$ of respondents stated that patients may modify therapy based on difficulties maintaining INR within therapeutic range (i.e. 2-3). Patient self-testing and self-management were not offered by $60 \%,(n=30)$ of respondents and $28 \%$, ( $n=14$ ) had never heard of such services. One respondent highlighted a possible rationale for this could be the limited remuneration and funds for the use of point-ofcare machines. It was also noted by another that pharmacists had a key role in counselling and education prior to discharge following a hospitalisation. A number of respondents highlighted that the role of decisionmaking around anticoagulation is usually lead by the physician, cardiologist or GP and often the nurses and patients input were minimal.

\section{Cardiovascular nurses' knowledge on warfarin interactions}

The majority of respondents $(n=34,69 \%)$ answered correctly that aspirin enhanced the effect of oral warfarin anticoagulation therapy. It is of concern that $48 \%(n=23)$ of respondents answered incorrectly to interactions

Table 5 Clinical decision making in anticoagulation

\begin{tabular}{|c|c|c|c|c|c|c|}
\hline Statement & $\begin{array}{l}\text { SD } \\
n(\%)\end{array}$ & $\begin{array}{l}\mathrm{D} \\
n(\%)\end{array}$ & $\begin{array}{l}\mathrm{N} \\
n(\%)\end{array}$ & $\begin{array}{l}\text { A } \\
n(\%)\end{array}$ & $\begin{array}{l}\text { SA } \\
n(\%)\end{array}$ & $\begin{array}{l}\text { Rating } \\
\text { Count }\end{array}$ \\
\hline $\begin{array}{l}\text { The risk of stroke versus the risk of bleeding is clearly articulated to } \\
\text { patients when commencing anticoagulation for stroke prevention in AF }\end{array}$ & $3(6)$ & $9(17)$ & $14(26)$ & $24(44)$ & $4(7)$ & 54 \\
\hline $\begin{array}{l}\text { I am unsure whether to advocate for thromboprophylaxis or not when } \\
\text { involved in team decisions }\end{array}$ & $7(13)$ & $22(41)$ & $14(26)$ & 10 (19) & $1(2)$ & 54 \\
\hline $\begin{array}{l}\text { It's difficult to decide where the benefits of thromboprophylaxis outweigh } \\
\text { the risks of hemorrhage }\end{array}$ & $3(7)$ & $27(50)$ & 10 (19) & $14(26)$ & $0(0)$ & 54 \\
\hline $\begin{array}{l}\text { I feel I do not know enough about the risk and benefits of different } \\
\text { anticoagulants }\end{array}$ & $5(9)$ & $30(57)$ & $4(8)$ & $12(23)$ & $2(4)$ & 53 \\
\hline $\begin{array}{l}\text { I take time to understand my patients views on the risks and benefits of } \\
\text { anticoagulation }\end{array}$ & $0(0)$ & $7(13)$ & 10 (19) & $31(58)$ & $6(11)$ & 54 \\
\hline $\begin{array}{l}\text { Generally, my patients are well informed about the risks and benefits of } \\
\text { anticoagulation at time of commencement }\end{array}$ & $3(6)$ & $8(15)$ & $11(20)$ & $28(52)$ & $4(7)$ & 54 \\
\hline $\begin{array}{l}\text { My patients receive comprehensive education about anticoagulation } \\
\text { prior to discharge }\end{array}$ & $2(4)$ & $5(9)$ & 10 (19) & $26(48)$ & $11(20)$ & 54 \\
\hline $\begin{array}{l}\text { I use the CHADS2 or CHA2DS2-VASc scores with patients to help risk } \\
\text { stratify stroke risk in clinical practice }\end{array}$ & $6(12)$ & $12(23)$ & $15(29)$ & $13(25)$ & $6(12)$ & 52 \\
\hline $\begin{array}{l}\text { I use the HAS-BLED score with patients to help risk stratify bleeding risk in } \\
\text { clinical practice }\end{array}$ & $11(22)$ & $13(26)$ & $16(31)$ & $9(18)$ & $2(4)$ & 51 \\
\hline $\begin{array}{l}\text { I use shared decision making with patients to explain the risks and benefits } \\
\text { of anticoagulation for stroke prevention in AF }\end{array}$ & $5(9)$ & $7(13)$ & $14(26)$ & $23(43)$ & $5(9)$ & 54 \\
\hline
\end{tabular}


Table 6 Barriers to anticoagulation

\begin{tabular}{lll}
\hline Variable (Barrier) & $\mathrm{n}=\mathrm{Y}(\%)$ & Rate count \\
\hline Fear of the patient falling & $39(70)$ & 52 \\
Lack of social support & $21(41)$ & 51 \\
(e.g. patient living alone or lack of caregiver) & & \\
Fear of poor adherence to medication taking & $36(71)$ & 51 \\
Fear of poor compliance to routine monitoring & $39(75)$ & 52 \\
(e.g. INR checking) & & \\
Fears of poor literacy & $13(26)$ & 50 \\
\hline
\end{tabular}

related to ibuprofen and $48 \%(n=23)$ did not know of interactions with topical salicylates. Whilst ibuprofen has no effect on oral anticoagulant therapy, it may impact on overall haemostasis and may increase the risk of gastrointestinal bleeding when used in combination with oral anticoagulants [15]. Only $23 \%(n=11)$ of respondents answered correctly that topical salicylates enhance oral warfarin anticoagulant therapy. Whilst results of how cardiac agents including propanolol, cholestyramine and atenolol trend towards the correct answers (propanolol enhancing, cholestyramine inhibiting and atenolol having no effect), the rate of respondents who did not know the interactions of these cardiac agents on warfarin therapy was 44-67\%. Only 9-22\% answered the questions on warfarin interactions with gastrointestinal agents correctly. More than two-thirds answered "don't know" to the question on sucralfate-warfarin interaction. The majority of respondents did not know how any of the vitamin supplements listed affected warfarin therapy (range 42-58\% across the 5 supplements). The questions on the interaction between antibiotics and warfarin were poorly completed; the majority of respondents answered "don't know". Results on warfarin interactions are summarised in Table 11.

Table 7 Factors facilitating optimal management of thromboprophylaxis

- Case Management

- Good GP/GP support

- Ease of access to INR checking

- Education

- Counselling assessment

- Discharge planning

- Follow up

- Family support \& involvement

- A HAS-BLED and CHADS2 Score

- Open discussion and understanding

of thromboprophylaxis

- Good understanding of risks

and benefits

- Pharmacy education

- Regular adherence and INR

monitoring

listening, interpreters, written info) - Warfarin booklets (written information)

- Self-management \& community support

- Careful assessment, reassessment of factors if change

- Monitoring of adherence

- Ensuring type of lifestyle and therapy is matched with patients capacity to self-manage - Nurse-led anticoagulation clinics
Table 8 Nurse's general comments to thromoprophyalxis use General comments about thromboprophylaxis use in patients with AF

"new agent dabigatran easier to manage patients"

"If medical officers have had a patient with a bleed, I find it makes them more cautious with subsequent patients"

"Some INR levels are very hard to control despite well-educated and compliant patient. Need new ideas i.e. Watchman LAA devices"

"It's variable and physician choice"

"Until an antidote is developed for the newer anticoagulants we don't use them. In some rare cases we do but often last choice"

"Dr's do all the decision making. Uses $\mathrm{CHADS}_{2} / \mathrm{CHA}_{2} \mathrm{DS}_{2}$ VASC"

"Quick uptake of NOAC agents but often without evidence (e.g. prosthetic valves \& AF)"

\section{Cardiovascular nurses' knowledge on warfarin related advice}

There were eight questions that assessed cardiovascular nurse's knowledge on warfarin advice. Responses are summarised in Table 11. Most questions were answered correctly with the exception of advice around warfarin use and pregnancy. $70 \%(n=34)$ of respondents knew that patients who are taking warfarin can consume spinach, however that they need to eat the same amount regularly every week. Over half (55\%, $n=26)$ correctly answered that consuming three glasses of wine will cause an increased in INR. Yet, $21 \%(n=10)$ of respondents did

Table 9 Cardiovascular nurses' practice patterns; use of oral anticoagulants, involvement in oral anticoagulation therapy and use of patient INR self-management

\begin{tabular}{ll}
\hline Question & $n(\%)$ \\
\hline Oral anticoagulants in use in daily practice & \\
- Warfarin (Coumadin) & $51(100)$ \\
- Dabigatran (Pradaxa) & $33(65)$ \\
- Rivaroxaban (Xareltro) & $33(65)$ \\
- Apixaban (Eiliquis) & $11(22)$ \\
Will patients be offered a choice of drug? & \\
- No, all patients will be put on warfarin first & $1(2)$ \\
- Some patients may be offered new anticoagulation & $41(82)$ \\
- Most patients will be given a choice & $8(16)$
\end{tabular}

Will patients on warfarin be able to change to one of the new drugs?

- No, they will need to stay on warfarin

- May change if difficulties keeping INR in therapeutic range

- Any patient can change to one of the new drugs

Do you offer patients INR self-testing or self-management?

- Both self-testing and self-management of INR

- Only self-testing of INR

- Neither self-testing nor self-management

The role of nurses regarding anticoagulants in your country

- Do not have a specific role

- Counsel patients regarding adherence to drug regimen

- Advice patients on dosing warfarin based on INR results

$34(65)$

- Teach about drugs, how to take them and side effects 
Table 10 Cardiovascular nurses' knowledge on warfarin-drug interactions

\begin{tabular}{|c|c|c|c|c|c|}
\hline \multirow[t]{2}{*}{ Question } & $n(\%)$ & $n(\%)$ & $n(\%)$ & $n(\%)$ & \\
\hline & Enhance & Inhibit & No effect & Don't know & Rating Count \\
\hline \multicolumn{6}{|c|}{ How to these anti-inflammatory agents affect oral warfarin anticoagulant therapy? } \\
\hline $\begin{array}{l}\text { - Aspirin } \\
\text { - Ibuprofen } \\
\text { - Topical salicylates }\end{array}$ & $\begin{array}{l}34(69) \\
23(48) \\
11(23)\end{array}$ & $\begin{array}{l}2(4) \\
8(17) \\
3(6)\end{array}$ & $\begin{array}{l}9(18) \\
\mathbf{9}(\mathbf{1 8 )} \\
11(23)\end{array}$ & $\begin{array}{l}4(8) \\
8(17) \\
23(48)\end{array}$ & $\begin{array}{l}49 \\
48 \\
48\end{array}$ \\
\hline \multicolumn{6}{|c|}{ How do these cardiac agents affect oral warfarin anticoagulant therapy? } \\
\hline $\begin{array}{l}\text { - Propanolol } \\
\text { - Cholestyramine } \\
\text { - Atenolol }\end{array}$ & $\begin{array}{l}7(15) \\
0(0) \\
5(11)\end{array}$ & $\begin{array}{l}2(4) \\
10(21) \\
1(2)\end{array}$ & $\begin{array}{l}15(32) \\
6(13) \\
20(44)\end{array}$ & $\begin{array}{l}23(49) \\
32(67) \\
20(44)\end{array}$ & $\begin{array}{l}47 \\
48 \\
46\end{array}$ \\
\hline \multicolumn{6}{|c|}{ How do these gastrointestinal agents affect warfarin anticoagulant therapy? } \\
\hline $\begin{array}{l}\text { - Antiacids } \\
\text { - Cimetidine } \\
\text { - Metamucol } \\
\text { - Sucralfate }\end{array}$ & $\begin{array}{l}0(0) \\
\mathbf{4}(9) \\
1(2) \\
0(0)\end{array}$ & $\begin{array}{l}23(49) \\
11(24) \\
10(22) \\
10(22)\end{array}$ & $\begin{array}{l}7(15) \\
4(9) \\
\mathbf{5}(11) \\
5(11)\end{array}$ & $\begin{array}{l}17(36) \\
27(59) \\
30(65) \\
30(67)\end{array}$ & $\begin{array}{l}47 \\
46 \\
46 \\
45\end{array}$ \\
\hline \multicolumn{6}{|c|}{ How do these vitamin supplement (s) affect oral anticoagulant therapy? } \\
\hline $\begin{array}{l}\text { - Multivitamin } \\
\text { - Multivitamin and minerals } \\
\text { - Antioxidant formula } \\
\text { - } 1200 \text { IU vitamin E } \\
\text { - } 1000 \text { mg vitamin C }\end{array}$ & $\begin{array}{l}2(4) \\
2(4) \\
7(16) \\
18(39) \\
4(9)\end{array}$ & $\begin{array}{l}9(20) \\
9(20) \\
3(7) \\
5(11) \\
3(7)\end{array}$ & $\begin{array}{l}15(33) \\
15(33) \\
9(21) \\
3(7) \\
12(27)\end{array}$ & $\begin{array}{l}19(42) \\
19(42) \\
25(57) \\
20(44) \\
26(58)\end{array}$ & $\begin{array}{l}45 \\
45 \\
44 \\
46 \\
45\end{array}$ \\
\hline \multicolumn{6}{|c|}{ Most antibiotics affect warfarin therapy by the process of: } \\
\hline $\begin{array}{l}\text { - Potentiation } \\
\text { - Inhibition } \\
\text { - Both } \\
\text { - Neither (other process) }\end{array}$ & & $\begin{array}{l}7(23) \\
5(17) \\
6(19) \\
1(4)\end{array}$ & $\begin{array}{l}0(0) \\
0(0) \\
1(4) \\
2(8)\end{array}$ & $\begin{array}{l}24(78) \\
25(84) \\
25(78) \\
23(89)\end{array}$ & $\begin{array}{l}31 \\
30 \\
32 \\
26\end{array}$ \\
\hline
\end{tabular}

Correct answers are shown in bold

not know the answer to this question. $88 \%(n=44)$ of cardiovascular nurses knew that the best time of day to take warfarin was the evening, and $90 \%(n=45)$ were aware that patients with a stable INR should have it checked every 4 weeks. Only $58 \%(n=29)$ of nurses would have given correct advice to patients on the action to take if a patient remembered missing a last dose. Over three quarters $(76 \%, n=38)$ of respondents correctly answered that once warfarin is ceased, it takes 5 days to be cleared from the patient's body. Most ( $84 \%, n=43$ ) nurses correctly identified that the length of time a patient is expected to be taking warfarin is patient centric, and dependant on individual needs. Only $12 \%(n=6)$ of respondents correctly answered that women who are pregnant can safely take warfarin during the second and third trimester. Less than half, $48 \%(n=24)$ of respondents incorrectly answered this question, wrongly identifying that pregnant women should not take warfarin, which is concerning around the correct information provision to this patient population.

\section{Discussion}

This study demonstrates that cardiovascular nurses in Australia and New Zealand have insufficient knowledge on oral anticoagulant therapy, warfarin-diet, and warfarinmedication interactions. Our findings are consistent with recent international research $[7,9]$. The less extensive reported use of novel agents may be due to their gradual introduction to the Pharmaceutical Benefit Scheme (PBS). The PBS is the national pharmaceutical rebate scheme providing medicines at a government-subsidised price. It is of concern that such a small percentage stated that most patients would be given a choice of anticoagulant. There remains considerable scope for improvement in this area of shared decision-making.

The lack of knowledge of warfarin-medication interactions is alarming. It is of concern at the lack of knowledge on warfarin related advice, particularly pertaining to pregnancy and how alcohol affects INR. Our findings represent a typically older and more experienced cardiovascular nursing population, working in specialised positions with advanced qualifications. And as such, are likely to be more knowledgeable on anticoagulation than other nurses. Given the overall poor results, it is feared that knowledge is likely to be even poorer in the broader nursing population.

\section{Practice patterns}

The cardiovascular nurses surveyed stated that warfarin remains the most widespread oral anticoagulant for stroke prevention in AF, whilst NOACs are reported to have lesser usage. It is concerning that only $16 \%$ of respondents stated that most patients would be given a choice. It appears that there is scope for improvement in the practice of shared 
Table 11 Cardiovascular nurses knowledge on how to advise patients on warfarin

\begin{tabular}{ll}
\hline Question & $\mathrm{n}(\%)$ \\
\hline While on warfarin the patient: & \\
- Should not eat spinach & $9(18)$ \\
- Can eat spinach once a month & $1(2)$ \\
- Can eat as much spinach as he & $2(4)$ \\
likes whenever he likes & \\
- Can eat spinach but needs to eat & $\mathbf{3 4}(\mathbf{6 9 )}$ \\
the same amount every week & $3(6)$ \\
- Don't know & 6 \\
- Skipped question &
\end{tabular}

While out with friends for dinner, your patient has just finished his third glass of wine. This amount of alcohol consumed in a single evening will:

$\begin{array}{ll}\text { - Cause a decrease in INR } & 7(15) \\ \text { - Cause an increase in INR } & \mathbf{2 6}(\mathbf{5 5}) \\ \text { - Does not affect warfarin in any way } & 3(6) \\ \text { - Make the patient sick when taking } & 1(2) \\ \text { warfarin medication } & \\ \text { - Don't know } & 10(21) \\ \text { - Skipped question } & 8\end{array}$

The best time of day to take warfarin is:

- At lunchtime $0(0)$

- In the evening

- In the morning before breakfast

- Any time of the day when you remember 3 (6)

- Don't know

- Skipped question

$1(2)$

Once the patient has reached a stable warfarin dose, a PT/INR blood test:

- Should be checked once a year

- Should be checked once every 3 months

- Should be checked at least once every 4 weeks

- Does not need to be checked once on a

stable warfarin does

- Don't know

- Skipped question 5

A patient just remembered that he forgot to take his warfarin medication dose last night. He/She should:

- Skip in the dose of warfarin he/she missed

- Take the missed warfarin dose right now

- Wait and take two doses right now

- Take one-half of the missed dose of

warfarin right now

- Don't know

- Skipped question

5

Once the patient's warfarin is stopped, how long does it take to get the medication out of his/ her system?

$\begin{array}{ll}\text { - } 5 \text { h } & 1(2) \\ \text { - } 5 \text { days } & \mathbf{3 8}(\mathbf{7 6}) \\ \text { - } 5 \text { weeks } & 2(4) \\ \text { - } 5 \text { months } & 0(0) \\ \text { - Don't know } & 9(18) \\ \text { - Skipped question } & 5\end{array}$

After starting warfarin, how long (in months/years) would you expect the patient to be taking warfarin?

$\cdot 1$ year

. 1 month

$0(0)$

- It depends on each person's needs
- If you start warfarin you will have to be

$0(0)$

$43(84)$

on the medication for the rest of your life

- Don't know

- Skipped question
Table 11 Cardiovascular nurses knowledge on how to advise patients on warfarin (Continued)

\begin{tabular}{ll}
\hline Women who are pregnant: & \\
- Should not take warfarin & $24(48)$ \\
- Can safely take warfarin during the second & $\mathbf{6}(\mathbf{1 2})$ \\
and third trimester & \\
- Can take warfarin but only need to take & $0(0)$ \\
it every others day & $0(0)$ \\
- Would not need to take warfarin, since being & \\
pregnant prevents them from getting blood clots & $20(40)$ \\
- Don't know & 5 \\
- Skipped question
\end{tabular}

Correct answers are shown in bold

decision-making and patient-centred care. It is important that nurses maintain an active role in the decision-making processes and act as an advocate for patients and caregivers. This may be particularly problematic when patients are presented with complex risk calculators and benefit statistics of various treatments. Patient self-testing and selfmanagement strategies have been not yet been embraced as innovative practices that support able patients. Barriers to patient self-management and self-testing include frailty, poor manual dexterity and cognitive dysfunction [12]; however these practices should not be discounted by clinicians. Additionally, a poor rebate for self-testing devices may also impede uptake in Australia and New Zealand. The nurse's role in education and counselling on anticoagulation was highlighted. Some respondents expressed that they often delegate this to the pharmacist for education. This practice appears commonplace, and is worrisome. A respondent expressed "most times, little education is given". This has immense implication for the quality of thromboprophylaxis.

\section{Knowledge}

Cardiovascular nurses must ensure that they are up-todate with current evidence-based information on AF and anticoagulation therapy to inform the education and care they provide to patients. Incorrect and inaccurate knowledge on drug-drug, drug-food interactions and monitoring requirements was prevalent among the respondents to our survey. This may lead to inappropriate patient counselling and education. This would adversely impact patient outcomes. It is therefore vital that cardiovascular nurses are knowledgeable and keep abreast with new information related to AF and anticoagulation practices. Support for self-testing and self-management practices must be preferred over teaching alone. Nurses are bestplaced to provide ongoing counselling throughout the spectrum of care; from hospitalisation to discharge and within primary care settings. However, the quality of this counselling is dependent on a strong contemporary knowledge base. Cardiovascular nurses must refrain from simple task delegation of anticoagulation education to 
pharmacists or other clinicians, it is important to adopt a combined and comprehensive approach. This may assist in optimising therapy, improving issues of adherence and ultimately patient outcomes. Clinicians must engage further with this topic to ensure safe care. Results from this study highlight the need for cardiovascular nurses to maintain a contemporary knowledge base. The Australian Health Practitioner Regulation Agency (AHPRA) mandates that all registered nurses must participate in at least $20 \mathrm{~h}$ of continuing nursing professional development per year that is relevant to the context of practice [16]. Education modules specific to AF and anticoagulation, including stroke and bleeding risk and lifestyle modification may be of assistance in maintaining minimum standards for continuing professional development for cardiovascular nurses.

\section{Limitations}

This study has some limitations. Firstly, whilst the response rate of $58 \%$ to the paper-based survey distributed during the conference is encouraging, the generalizability of these findings is difficult. These findings represent a typically older and more experienced cardiovascular nursing population, working in specialised positions with higher qualifications. Therefore this may not be representative of the general Australian and New Zealand cardiovascular nursing population whom provide bedside patient education on anticoagulation. Secondly, the majority of respondents $(80 \%)$ were attending a cardiovascular nursing conference, for many of the workforce this remains a privilege to secure funding and time to attend such professional development events. The seniority of respondents may reflect the demographic that normally attends conferences, hold a professional society membership or has access to a workplace email account. Again, this limits the generalizability of findings.

\section{Conclusions}

The results of our study demonstrate that of the cardiovascular nurses surveyed in Australia and New Zealand most had inadequate knowledge on oral anticoagulant therapy. There is need for improvement, to ensure quality of care for patients with AF receiving anticoagulation. Cardiovascular nurses need to be able to provide accurate, robust and timely advice to patients to topics including lifestyle, medication and food interactions to anticoagulation. A lack of knowledge on these topics may contribute to inappropriate counselling and education. Further, the communication of inaccurate information may implicitly reinforce myths and misconceptions around anticoagulation. The education of patients on anticoagulation is not a role of a single health professional. A team approach must be taken and nurses have a key role in providing answers to questions and sound clinical advice across all care settings. Future research should address modes of delivery of AF and anticoagulation education for clinicians, individuals and their caregivers.

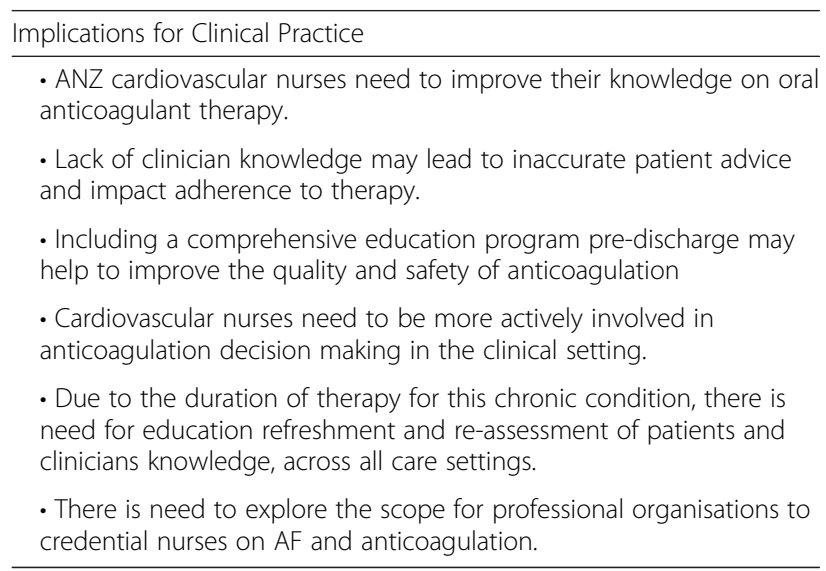

Competing interests

The authors have no conflicts of interest to declare.

\section{Authors' contributions}

CF: Study design, data collection, data analysis and interpretation, manuscript preparation. SCI: Study design, data collection, data analysis and interpretation, manuscript preparation. PJN: Study design, data collection, data analysis and interpretation, manuscript preparation. SM: data analysis and interpretation, interpretation, manuscript preparation. PSM: Study design, data analysis and interpretation, manuscript preparation. PMD: Study design, data analysis and interpretation, manuscript preparation. All authors read and approved the final manuscript.

\section{Acknowledgements}

The authors would like to express thanks to; Kjersti Oterhals et al. for granting permission to reproduce the survey items previously published in the European Journal of Cardiovascular Nursing 2014 Vol. 13(3) 261-269; the executive committee, members and delegates of the Australian Cardiovascular Nursing College; the nursing council executive committee and nurse members of the Cardiac Society of Australia and New Zealand; and all other participants for their support and contribution to the survey.

This research received funding from the Australian College of Nursing, through a grant of $\$ 5,000$ awarded in 2013 to support the 'Atrial Fibrillation and Stroke Thromboprophylaxis in hEart Failure' (AFASTER) Study. Dr. Caleb Ferguson is currently supported by a UTS Doctoral Scholarship (2012-2015). Associate Professor Sally C Inglis is currently supported by a Cardiovascular Research Network Life Science Research Fellowship supported by the Heart Foundation and the NSW Office for Medical Research (CR 11S 6226).

\section{Author details}

${ }^{1}$ Faculty of Health, University of Technology Sydney, Sydney, Australia. ${ }^{2}$ Centre for Cardiovascular and Chronic Care, Faculty of Health, University of Technology Sydney, Sydney, Australia. ${ }^{3}$ St Vincent's Health Australia (Sydney), Sydney, Australia. ${ }^{4}$ Australian Catholic University, Sydney, Australia. ${ }^{5}$ Heart Transplant Program, Sydney and Victor Chang Cardiac Research Institute, St Vincent's Hospital, Sydney, Australia. ${ }^{6}$ School of Nursing, Johns Hopkins University, Baltimore, USA.

Received: 27 October 2014 Accepted: 7 December 2015

Published online: 12 January 2016

\section{References}

1. Ball J, Carrington M, McMurray JJV, Stewart S. Atrial fibrillation: Profile and burden of an evolving epidemic in the 21st century. Int J Cardiol. 2013;167(5):1807-24. 
2. Shea JB, Sears SF. A patient's guide to living with atrial fibrillation. Circulation. 2008;117(20):e340-3.

3. Ferguson C, Inglis SC, Newton PJ, Middleton S, Macdonald PS, Davidson PM. Atrial fibrillation: Stroke prevention in focus. Australian Critical Care. 2013; 27(2):92-98.

4. Ferguson C, Inglis SC, Newton PJ, Middleton S, Macdonald PS, Davidson PM. Atrial fibrillation and thromboprophylaxis in heart failure: The need for patient-centered approaches to address adherence. Vasc Health Risk Manag. 2013;9(1):3-11.

5. Camm AJ, Lip GY, De Caterina R, Savelieva I, Atar D, Hohnloser SH, et al. 2012 focused update of the ESC Guidelines for the management of atrial fibrillation. Eur Heart J. 2012;33:2719-47.

6. Wann LS, Curtis AB, January CT, Ellenbogen KA, Lowe JE, Estes M, et al. 2011 ACCF/ AHA/ HRS focused update on the management of patients with atrial fibrillation: a report of the american college of cardiology foundation/ american heart association task force on practice guidelines. Circulation. 2011;1234:104-23.

7. Couris R, Tataronis G, McCloskey W, Oertel L, Dallal G, Dwyer J, et al. Dietary vitamin $\mathrm{K}$ variability affects International Normalized Ratio (INR) coagulation indices. International journal for vitamin and nutrition research. Internationale Zeitschrift fur Vitamin- und Ernahrungsforschung. Int I Vitam Nutr Res. 2006; 76(2):65-74.

8. Ferguson C, Inglis SC, Newton PJ, Middleton S, Macdonald PS, Davidson PM. The caregiver role in thromboprophylaxis management in atrial fibrillation: A literature review. Eur J Cardiovasc Nurs. 2015;14(2):98-107.

9. Oterhals K, Deaton C, De Geest S, Jaarsma T, Lenzen M, Moons P, et al. European cardiac nurses' current practice and knowledge on anticoagulation therapy. Eur J Cardiovasc Nurs. 2014;13(3):261-9.

10. Couris RR, Tataronis GR, Dallal GE, Blumberg JB, Dwyer JT. Assessment of healthcare professionals' knowledge about warfarin-vitamin K drug-nutrient interactions. J Am Coll Nutr. 2000;19(4):439-45.

11. Heneghan C, Alonso-Coello P, Garcia-Alamino JM, Perera R, Meats E, Glasziou P. Self-monitoring of oral anticoagulation: a systematic review and meta-analysis. Lancet. 2006;367(9508):404-11.

12. Dolor RJ, Ruybalid RL, Uyeda L, Edson RG, Phibbs C, Vertees JE, et al. An evaluation of patient self-testing competency of prothrombin time for managing anticoagulation: pre-randomization results of VA Cooperative Study \#481-The Home INR Study (THINRS). J Thromb Thrombolysis. 2010;30(3):263-75.

13. Gattellari M, Worthington J, Zwar N, Middleton S. Barriers to the use of anticoagulation for nonvalvular atrial fibrillation. Stroke. 2008:39:227-30.

14. Newton P, Davidson P, Sanderson C. On behalf of the improving palliative care through clinical trials group. An online survey of Australian physicians reported practice with the off-label use of nebulised frusemide. BMC Palliat Care. 2012;11(1):6

15. Ansell J, Hirsh J, Hylek E, Jacobson A, Crowther M, Palareti G. Pharmacology and management of the vitamin K antagonists. Chest. 2008;133(6 suppl):160S-98S.

16. Australian Health Practitioner Regulation Agency (AHPRA). Nursing and Midwifery Continuing Professional Development Registration Standard. 2010. Accessed 4th August 2014, 2014.

\section{Submit your next manuscript to BioMed Central and we will help you at every step:}

- We accept pre-submission inquiries

- Our selector tool helps you to find the most relevant journal

- We provide round the clock customer support

- Convenient online submission

- Thorough peer review

- Inclusion in PubMed and all major indexing services

- Maximum visibility for your research

Submit your manuscript at www.biomedcentral.com/submit

C Biomed Central 